ACADEMIA ROMÂNĂ Roum. Chim.,
Revue Roumaine de Chimie
http://web.icf.ro/rrch/

\title{
TURBIDITY REMOVAL FROM BENTONITE SUSPENSION BY COAGULATION/FLOCCULATION USING MODIFIED p-PHENYLENEDIAMINE/POLY(ACRYLAMIDE)
}

\author{
Brahim BOURAS,,${ }^{\mathrm{a} *}$ Tayeb HOCINE, ${ }^{\mathrm{a}}$ Karim BENHABIB,${ }^{\mathrm{b}}$ Redouane ZAIR, ${ }^{\mathrm{a}}$ Asma MANSRI, ${ }^{\mathrm{a}}$ \\ Lahcène TENNOUGA ${ }^{\mathrm{a}}$ and Kaddour GUEMRA ${ }^{\mathrm{c}}$ \\ ${ }^{a}$ Laboratory of Organic Electrolytes and Polyelectrolytes Application (LAEPO). Department of Chemistry, \\ Faculty of Science, Tlemcen University, B. P. 11913000 Tlemcen, Algeria \\ ${ }^{\mathrm{b}}$ Eco-Processes, Optimization and Decision Support (EPROAD, EA) - University of Picardie Jules Verne - IUT of Aisne - \\ 48 rue d'Ostende - 02100 Saint-Quentin - France \\ ${ }^{\mathrm{c}}$ Laboratory of Macromolecular Physical Organic Chemistry, Department of Chemistry, Faculty of Science, \\ Djillali Liabes University, Sidi Bel Abbes, Algeria
}

We were interested in this work by the modification of hydrolyzed poly (acrylamide) which allow us to obtain a new copolymer based on acrylamide and pphenylenediamine (PPD). The properties of the obtained copolymer and its structure and composition were established by ${ }^{1} \mathrm{H}$ NMR, FTIR spectroscopy's and by TGA analysis. The prepared copolymer was used as a flocculent substance in the aim to remove turbidity from wastewater. Several experimental parameters such as $\mathrm{pH}$ of water, initial turbidity, flocculent concentration and dyes concentration, and their effects on the flocculation process were studied. The considered results show that the studied copolymer is good flocculent and efficient at a very low optimum concentration.

\section{INTRODUCTION}

Contamination of water resources, especially in terms of quality, is a serious problem today. It is the result of the massive use of organic and minerals products in agriculture, urban and industrial fields. Wastewater from textile industry including dyes represents an important source of pollution. This field is a major environmental and health problems. For this purpose, it is essential to treat these wastes to limit the amount of pollutants discharged into the environment. There are several conventional techniques for eliminating the excess of colored organic pollutants for example methyl- ene blue. ${ }^{1-4}$ Coagulation/flocculation is one of the chemical treatment processes commonly used for water and wastewater. It has a wide range of application in water and wastewater facilities due to its efficiency and simple operation.,

Polyacrylamides have a great technical and academic importance. Due to their properties, modified polyacrylamide, and its derivatives are an extremely important class of synthetic copolymers widely used in industrial and laboratory applications. $^{7-9}$ Derived poly (acrylamide), copolymers are the important inputs for the treatment of drinking water and wastewater following the coagulation/flocculation properties

\footnotetext{
*Corresponding author: bourasbrahim_m8@yahoo.fr; Tel: 00213663415152
} 
from the action of charge neutralization and adsorption in the solid-liquid separation practice. ${ }^{10,11}$

We were interested in this work by the modification of the hydrolyzed poly (acrylamide) (AD37) by p-phenylenediamine (PPD). We have obtained by this reaction of modification a new copolymer based on acrylamide and PPD as shown in Fig. 1. The obtained copolymer was used as a flocculent substance with the objective to remove turbidity from wastewater. The effect of several experimental parameters such as the $\mathrm{pH}$ of the aqueous medium, initial turbidity and flocculent concentration were investigated.

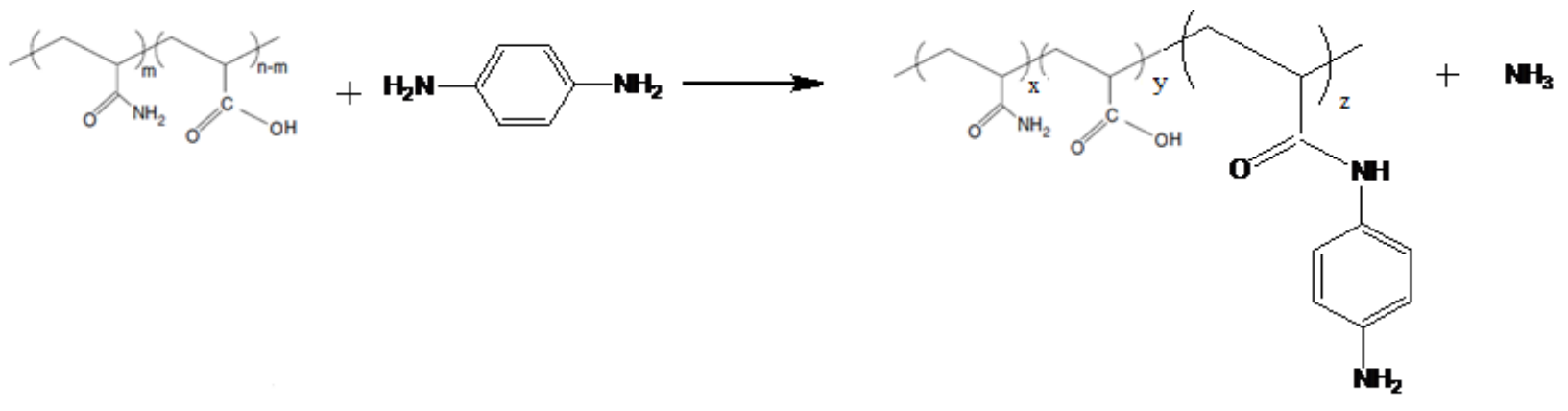

Fig. 1 - AD37-PPD copolymer obtained by modification of hydrolyzed poly(acrylamide) by p-phenylenediamine.

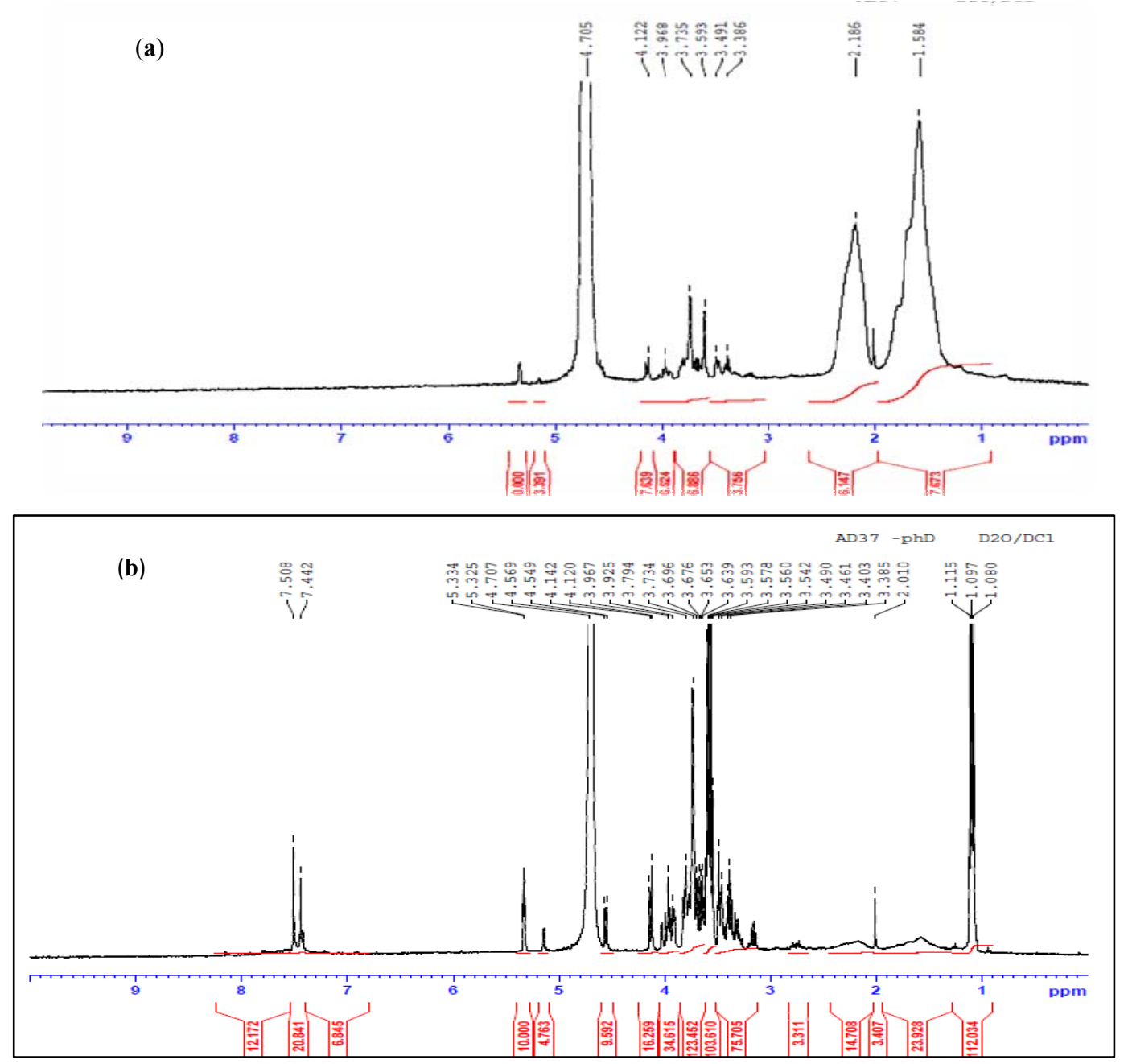

Fig. $2-{ }^{1} \mathrm{H}$ NMR Spectrum in $\mathrm{D}_{2} \mathrm{O} / \mathrm{DCl}$ mixture as solvent for AD37 copolymer; b) modified copolymer (AD37-PPD). 
Table 1

Characteristics ${ }^{1} \mathrm{HNMR}$ of AD37 and AD37-PPD copolymers in $\mathrm{D}_{2} \mathrm{O} / \mathrm{DCl}{ }^{12,13}$

\begin{tabular}{|c|c|c|c|}
\hline \multicolumn{2}{|c|}{ AD37 } & \multicolumn{2}{|c|}{ AD37-PPD } \\
\hline$\delta(\mathrm{ppm})$ & Attributions & $\delta(\mathrm{ppm})$ & Attributions \\
\hline 1.584 & $\begin{array}{c}\text { proton - } \mathrm{CH}_{2} \text { - copolymer } \\
\text { backbone }\end{array}$ & Between $1.080-1.115$ & $\begin{array}{c}\text { proton - } \mathrm{CH}_{2} \text { - copolymer } \\
\text { backbone }\end{array}$ \\
\hline 2.186 & $\begin{array}{c}\text { proton - } \mathrm{CH} \text { - copolymer } \\
\text { backbone }\end{array}$ & Between $1.5-2.2$ & $\begin{array}{c}\text { proton - } \mathrm{CH} \text { - copolymer } \\
\text { backbone }\end{array}$ \\
\hline Between $3.386-4.122$ & $\begin{array}{c}\text { protons - } \mathrm{NH}_{2} \text { function - } \\
\mathrm{CONH}_{2}\end{array}$ & Between $3.385-4.707$ & $\begin{array}{c}\text { protons - } \mathrm{NH}_{2} \text { - of AD37 } \\
\text { and PPD }\end{array}$ \\
\hline 4.705 & protons of solvent $\mathrm{D}_{2} \mathrm{O} / \mathrm{DCl}$ & Between $4.769-4.707$ & protons of solvent $\mathrm{D}_{2} \mathrm{O} / \mathrm{DCl}$ \\
\hline- & - & Between $5.325-5.334$ & proton $-\mathrm{NH}_{2^{-}}$of PPD \\
\hline- & - & Between $6.8-7.442$ & $\begin{array}{l}\mathrm{H} \text { atom at meta position of } \\
\text { protons in PPD phenyl ring }\end{array}$ \\
\hline- & - & Between $7.5-8.2$ & $\begin{array}{l}\mathrm{H} \text { atom at ortho position of } \\
\text { protons in PPD phenyl ring }\end{array}$ \\
\hline
\end{tabular}

\section{RESULTS AND DISCUSSION}

\section{Characterization of the modified copolymer}

\section{${ }^{1} \mathrm{H}$ NMR characterization}

The proton nuclear magnetic resonance $\left({ }^{1} \mathrm{H}\right.$ NMR) spectrum of the modified copolymer (AD37-PPD) and hydrolyzed poly(acrylamide) were realized with a DMX-500 (Bruker Company, Germany) in $\mathrm{D}_{2} \mathrm{O} / \mathrm{DCl}$ mixture as solvent. Figure $\mathbf{2 a}$ and $\mathbf{2 b}$ shows the ${ }^{1} \mathrm{H}$ NMR spectrum of AD37PPD copolymer compared with AD37 copolymer.

The purpose of this characterization by ${ }^{1} \mathrm{H}$ NMR is to confirm the structure of the modified copolymer. We notice the presence of several peaks corresponding to all the protons $\mathrm{H}$ in the copolymers. They are assigned to different protons, which confirm the presence of PPD molecules in the modified copolymer (AD37-PPD). (Table 1) gives the attributions of the peaks of AD37 and AD37-PPD copolymers. ${ }^{12,13}$

\section{Infra-red spectroscopy (FTIR)}

The IR spectra were recorded on an FTIR Cary 600 spectrophotometer used in Laboratory of Application of Electrolytes and Polyelectrolytes Organics (LAEPO), at University of Tlemcen, Algeria. Figure 3 shows the AD37-PPD spectrum (below) and the AD37 spectrum (above).

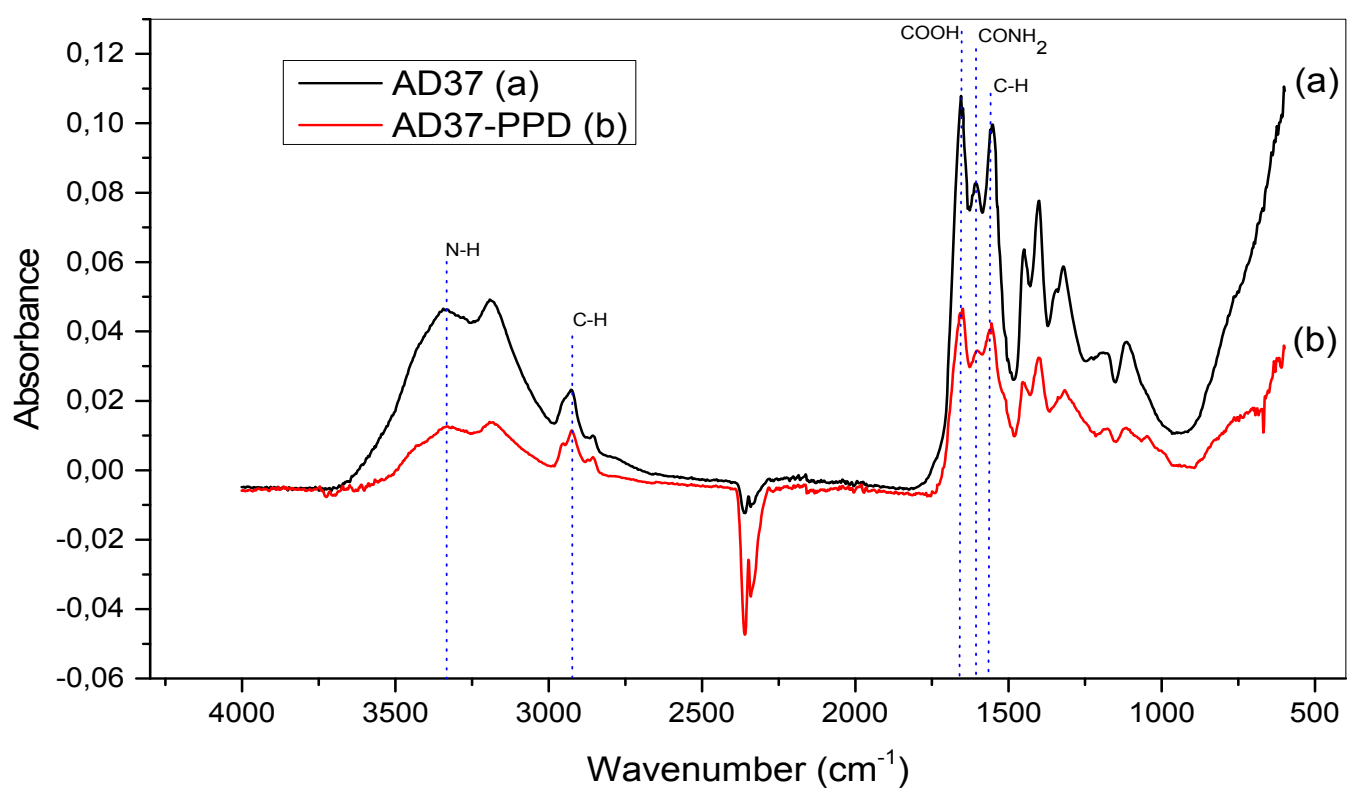

Fig. 3 - IR spectra (FTIR): a) AD37-PPD copolymer; b) AD37 copolymer. 
Table 2

Vibration bands of the partially hydrolyzed polyacrylamide (AD37) and the modified copolymer (AD37-PPD) ${ }^{14}$

\begin{tabular}{|c|c|c|c|}
\hline \multicolumn{2}{|c|}{ Frequency $v\left(\mathrm{~cm}^{-1}\right)$} & Attribution & Nature \\
\hline AD37 & AD37- PPD & & \\
\hline 3334 & 3332 & $\mathrm{~N}-\mathrm{H}$ & Stretching \\
\hline 2926 & 2924 & $\mathrm{C}-\mathrm{H}$ & Stretching \\
\hline 1654 & 1655 & $\mathrm{C}=\mathrm{O}(\mathrm{COOH})$ & Stretching \\
\hline - & 1602 & $\mathrm{C}=\mathrm{O}\left(\mathrm{CONH}_{2}\right)$ & Stretching \\
\hline 1552 & 1555 & $\mathrm{C}-\mathrm{H}$ & Bending \\
\hline 1384 & 1384 & $\mathrm{C}-\mathrm{N}$ & Stretching \\
\hline
\end{tabular}

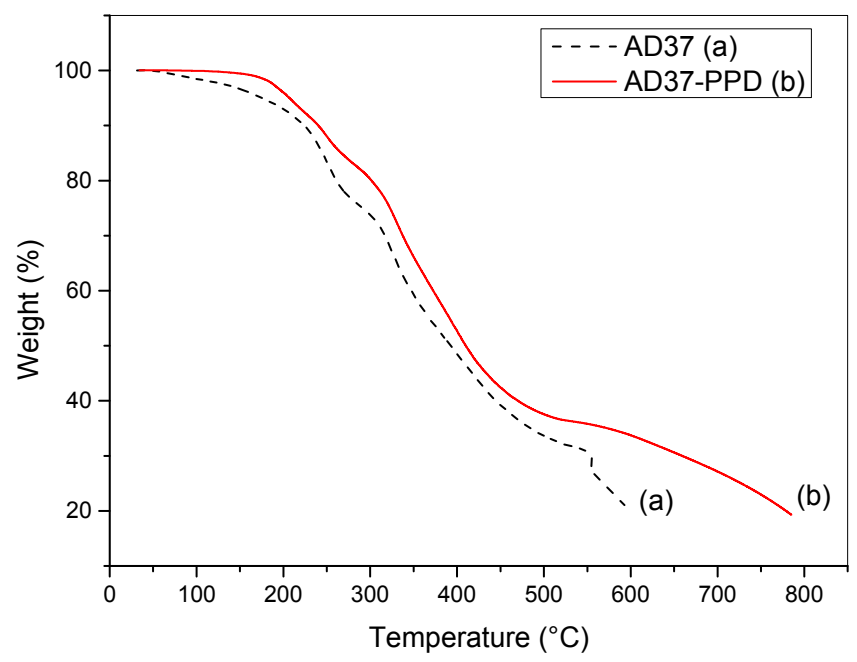

Fig. 4 - Temperature dependence of weight loss (TGA) for:

(a) Hydrolyzed polyacrylamide (AD37); (b) Modified copolymer (AD37-PPD).

The FTIR analysis was used to confirm the PPD adsorption onto the AD37 copolymer (Table 2) gives the attributions of bands of AD37 and AD37PPD copolymers. ${ }^{14}$

\section{Thermogravimetric analysis (TGA)}

The thermogravimetric analysis is an important method for the study of the thermal stability of this copolymer. Thermogravimetry experiment was carried out on a TA Instruments Q600 (LAEPOLaboratory). Measurements were performed under the air atmosphere. The same conditions were used for tests, with heating rate of $10{ }^{\circ} \mathrm{C} / \mathrm{min}$ in the range of temperature between 50 and $800{ }^{\circ} \mathrm{C}$ under the air flow. The thermal decomposition behavior of AD37-PPD compared to the AD37 copolymers was shown in (Figure 4).

Thermogram of AD37 copolymer is depicted in curve 4a. We note that an initial weight loss between 50 and $200{ }^{\circ} \mathrm{C}$ is observed due to the residual water and solvent. The decomposition of this copolymer is between 250 and $500{ }^{\circ} \mathrm{C}$ with a weight loss at approximately $60 \%$. It is ascribed to carbonization and imines reactions of the amide groups. The copolymer is completely decomposed at approximately $600{ }^{\circ} \mathrm{C}$. While the decomposition of the AD37-PPD copolymer begins at approximately $210{ }^{\circ} \mathrm{C}$ up to $500{ }^{\circ} \mathrm{C}$ with a weight loss of $52 \%$. The decomposition of the AD37-PPD copolymer is at a higher temperature compared to the AD37 copolymer. As well, the modified copolymer has a good thermal stability. This result confirms the modification of the AD37 by the PDD.

\section{Study of the Natural Settling of Bentonite Suspensions}

Bentonite settlement kinetics have been studied with different initial concentrations of Bentonite (50, 100 and $150 \mathrm{mg} / \mathrm{L}$ ) with the following turbidities 10, 28 and 35 NTU. For this, we used beaker $(1000 \mathrm{~mL})$ which contains $300 \mathrm{~mL}$ of each Bentonite concentrations. Samples are taken to measure the residual turbidity. Figure 5 represents the kinetics of the natural settling of bentonite suspensions for the different Initial concentrations. 


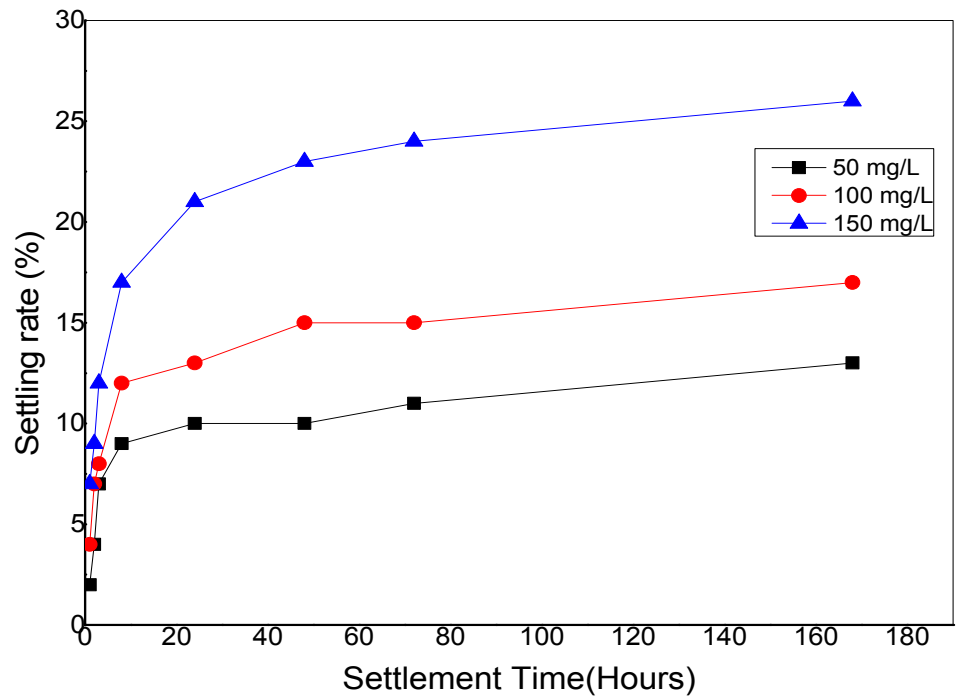

Fig. 5 - Settling rate of natural Bentonite suspension as a function of time at $25^{\circ} \mathrm{C}$.

From the reported results we can conclude that the natural settling of bentonite suspensions is a very slow process. Indeed, for a Bentonite concentration of $150 \mathrm{mg} / \mathrm{L}, 26 \%$ of elimination is achieved after one week of settling. We note that the natural sedimentation of high concentration of bentonite is very slow processes which agree with the results of literature. ${ }^{15,16}$

\section{Application of AD37-PPD copolymer to the removal of turbidity from Bentonite suspensions by coagulation / flocculation}

\section{pH and concentration of AD37-PPD effect on bentonite settling}

The AD37-PPD copolymer is used as a flocculent, in order to eliminate the turbidity of bentonite suspensions. However, the procedure of JAR-TEST described previously is respected throughout the experimental section. To evaluate the $\mathrm{pH}$ effect on the coagulation /flocculation efficiency and to determine the optimal $\mathrm{pH}$, coagulation / flocculation of bentonite suspension $(100 \mathrm{mg} / \mathrm{L})$ is achieved by adding various concentrations of AD37-PPD for different values of $\mathrm{pH}$. The initial turbidity of bentonite suspension is $\mathrm{T}_{0}=28 \mathrm{NTU}$. At the end of the operation the solutions are left to settle, and the final turbidity of the supernatant is measured after $10 \mathrm{~min}$. The obtained results are represented in (Figure 6), the percentage of the removed turbidity is plotted according to the concentration of the AD37-PPD copolymer at different $\mathrm{pH}$ values. The AD37-PPD copolymer shows low efficiency of turbidity removal in the basic medium $(\mathrm{pH}>6.15)$. It reaches a maximum of $32.15 \%$ at a concentration of $2 \mathrm{mg} / \mathrm{L}$.

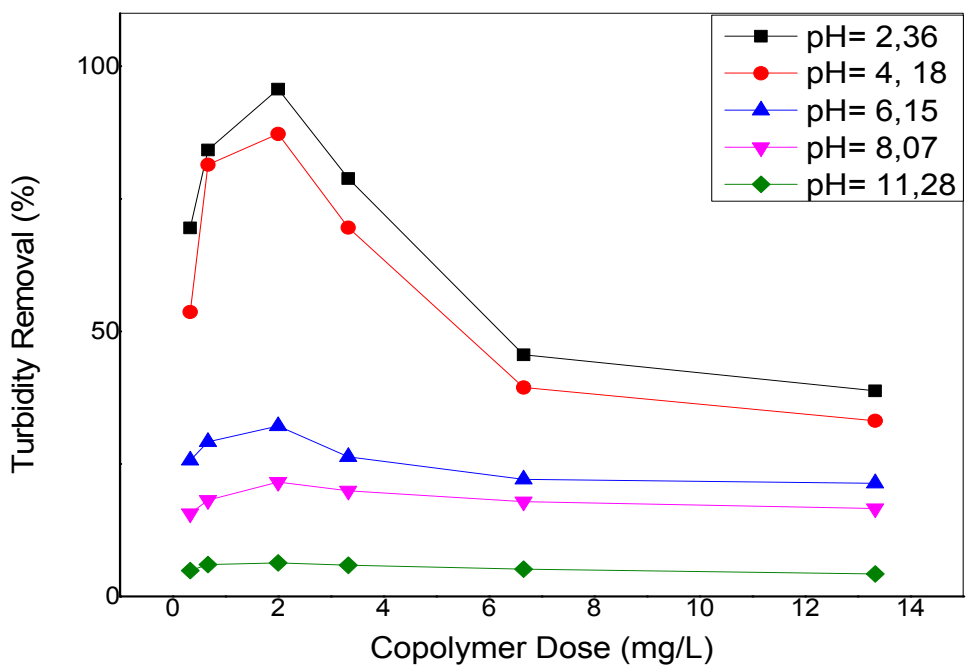

Fig. 6 - Turbidity removal from bentonite suspension as a function of AD37-PPD concentration for different values of $\mathrm{pH}$ at $25^{\circ} \mathrm{C}$ and $\mathrm{t}=10 \mathrm{~min}$. 


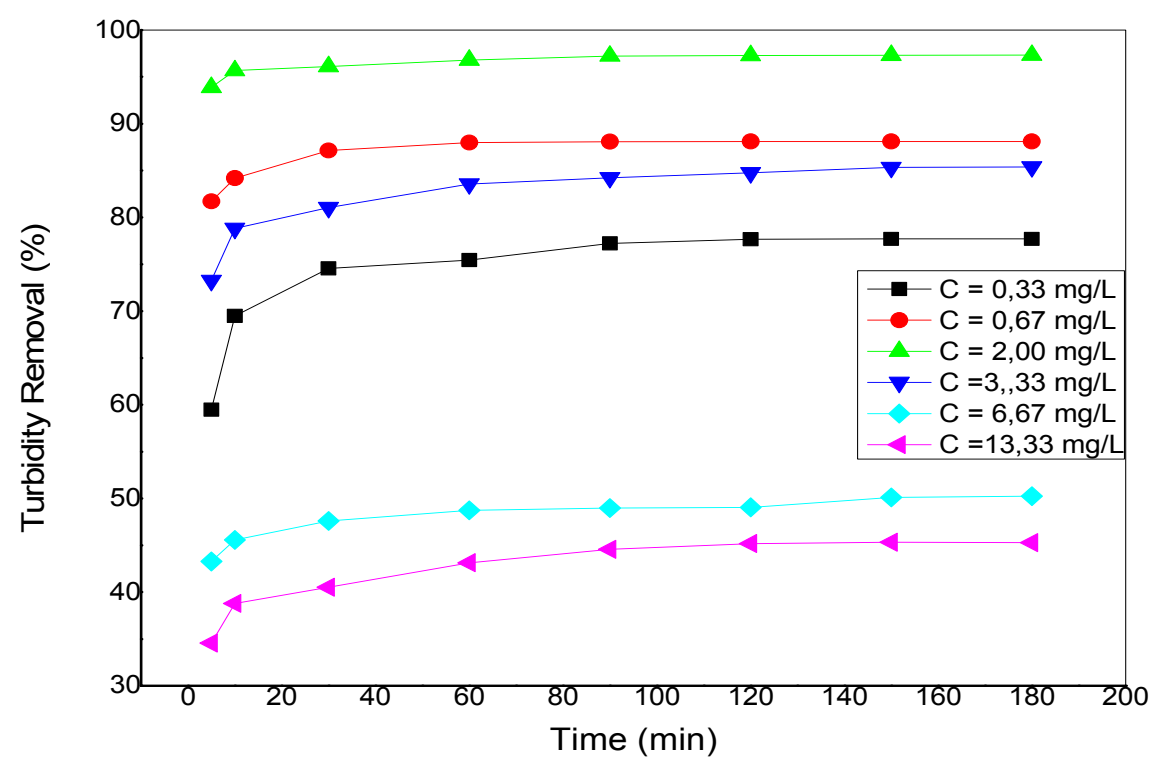

Fig. 7 - Kinetics of the settling bentonite in the presence of different concentrations of the AD37-PPD copolymer at $\mathrm{pH}=2.36$.

This can be explained by the absence of positively charged sites which play the leading role in the removal mechanism of negatively charged bentonite particle by charge neutralization. ${ }^{17} \mathrm{~A}$ good flocculent behavior is shown by the AD37PPD copolymer in acid medium. At $\mathrm{pH}=2.36$, the turbidity removal efficiency achieved a percentage of $95.67 \%$ with a copolymer concentration of $2 \mathrm{mg} / \mathrm{L}$. This result is related to the adsorption of the negatively charged bentonite particles on the surface of the copolymer on the ammonium $\left(-\mathrm{NH}_{3}{ }^{+}\right)$sites created by the addition of $\mathrm{HCl}$ acid.

\section{Study of kinetic flocculation of bentonite suspensions}

To study the evolution of coagulation / flocculation process in the removal of turbidity, supernatant turbidity is measured at different settling time. The obtained results are illustrated in Fig. 7.

This figure represents the variation of the turbidity removal percentage as a function of decantation time in the presence of different AD37-PPD copolymer concentration at $\mathrm{pH}=2.36$. These results show a slight improvement with all copolymer concentration as a function of time. We can say that the flocs formed are stable and do not destroy themselves.

\section{MATERIALS AND METHODS}

\section{Materials}

The hydrolyzed polyacrylamide (AD37) was provided from Rhône-Poulenc (France). Its rate carboxylate function is $\tau=0.27$, as determined by ${ }^{13} \mathrm{C}$ NMR and potentiometry. Its weight-average molar mass is $5 \times 10^{6} \mathrm{~g} / \mathrm{mol}$ which is estimated by light scattering. ${ }^{18-20}$

The p-phenylenediamine $\left(\mathrm{NH}_{2}-\varphi-\mathrm{NH}_{2}\right)$ (PPD) was provided by Aldrich. It is poorly soluble in water and soluble in ethanol. Its molecular mass is $108 \mathrm{~g} / \mathrm{mol}$. Absolute ethanol was from Aldrich and was used as a non-solvent for the copolymer. The bi-distilled water was used as solvent for the copolymer; its $\mathrm{pH}$ value is about 6 . Bentonite has particular water adsorption properties; however modified Bentonite can adsorb various substances. ${ }^{21}$ A sample of Bentonite (BC) was supplied by a local company issued from the fields of Hammam Boughrara-Maghnia, Algeria. It is composed essentially of montmorillonite. ${ }^{16}$ The different chemical elements and proprieties of the Bentonite are mentioned in a previous work of Mansri et al. ${ }^{22}$

\section{Methods}

At $25 \pm 1{ }^{\circ} \mathrm{C}$, flocculation experiments were carried out in a conventional Jar-Test apparatus. It consisted of six paddles on a bench. The paddles were connected to each other by a gear mechanism, and all these paddles were simultaneously rotated by the same motor at a controlled speed and time. Wastewater samples of $1000 \mathrm{~mL}$ each were transferred to the jars and then $\mathrm{pH}$ adjusted using $\mathrm{HCl}(1 \mathrm{M})$ or $\mathrm{NaOH}(1 \mathrm{M})$ solutions. The required dose of modified copolymer (AD37-PPD) was added to each beaker. Directly after the addition of the copolymer 
dosage, the wastewater sample in the jar was stirred rapidly at a paddle speed of $120 \mathrm{rpm}$ for 2 min then stirred slowly at a paddle speed of $50 \mathrm{rpm}$ for $10 \mathrm{~min}$. Finally, the treated wastewater could settle for 5 min. ${ }^{23}$

For assessing flocculent efficiency, we use a turbidimeter to measure the initial turbidity $\left(\mathrm{T}_{0}\right)$ and so the turbidity of the suspension after adding different amounts of the flocculent $(0.1-5 \mathrm{ppm})$ $\left(T_{\mathrm{f}}\right)$. The turbidity removal percent was calculated from the formula: ${ }^{17,24}$

$$
\text { Turbidity removal } \%=\frac{\left(T_{0}-T_{f}\right)}{T_{0}} \times 100
$$

\section{Synthesis of the modified poly(acrylamide) (AD37-PPD)}

The synthesis of our copolymer was carried out by modification of hydrolyzed polyacrylamide (AD37) by the p-phenylenediamine (PPD) according to the following procedure: in a $100 \mathrm{~mL}$ beaker, we introduce $2.5 \mathrm{~g}$ of hydrolyzed polyacrylamide (AD37) containing $30 \mathrm{~mL}$ of bidistilled water, then we leave under stirring for 24 hours. In a $25 \mathrm{~mL}$ flask, we prepare an aqueous solution of p-phenylenediamine $\left(\mathrm{NH}_{2}-\varphi-\mathrm{NH}_{2}\right)$ (PPD) acidulated with $\mathrm{HCl}$. We added $10 \mathrm{~mL}$ of the aqueous solution of PPD to the aqueous solution of AD37 in the beaker. Stirring and heating were maintained for 2 hours. The resulting product was dissolved and then precipitated in a large amount of ethanol. The product was dried at $70{ }^{\circ} \mathrm{C}$ for 24 hours.

\section{CONCLUSIONS}

The flocculation of turbid water using jar test is performed in different low, medium and high turbidity level. The flocculation experiments using modified Poly(acrylamide) AD37-PPD solutions indicated that flocculation process effectively removed turbidity from water. The AD37-PPD copolymer shows low efficiency of turbidity removal in the basic medium $(\mathrm{pH}>6.15)$ with a maximum of $32.15 \%$ with a concentration of $2 \mathrm{mg} / \mathrm{L}$. A good flocculent behavior is shown by this copolymer in acidifying the starting medium. A percentage of $95.67 \%$ is achieved with a concentration of $2 \mathrm{mg} / \mathrm{L}$ at $\mathrm{pH}=2.36$. This result provided by the adsorption of bentonite particle negatively charged on the copolymer by the addition of $\mathrm{HCl}$ acid.

Acknowledgements. The authors thank the National Agency for the Development of University Research (ANDRU) in Algeria for financial support.

\section{REFERENCES}

1. Y. Bulut and H. A. Aydin, Desalination, 2006, 194, 259267.

2. A. Rathinam, R. Rao and U. Nair, J. Taiwan. Inst. Chem. Eng., 2011, 42, 952-956.

3. T. Robinson, G. Mcmullan, R. Marchant and P. Nigam, Bioresour. Technol., 2001, 77, 247-255.

4. M. J. Ahmed and S. K. Dhedan, Flui. Phas. Equil., 2012, 317, 9-14.

5. J. P. Wang, Y. Z. Chen, X. W. Ge and H. Q. Yu, Colloid. Surf. A., 2007, 302, 204-210.

6. H. Zheng, G. Zhu, S. Jiang, T. Tshukudu, X. Xiang, P. Zhang and Q. He, Desalination, 2011, 269, 148-156.

7. A. Mansri, B. Bouras and T. Hocine, Mor. J. Chem., 2017, 5, 25-34.

8. G. Bastiat, B. Grassl and J. Francois, Polym. Int., 2002, 51, 958-965.

9. B. D. Hatice, E. M. Celia, H. K. Jean and K. M. Orhun, Biomaterials, 2009, 30, 589-596.

10. A. Baghvand, Z. A. Daryabeigi, N. Mehrdadi and A. Karbassi, Am. J. Environ. Sci., 2010, 6, 442-448.

11. M. A. Yukselen and J. Gregory, J. Chem. Technol. Biot., 2004, 79, 782-788.

12. B. Bouras, A. Mansri, L. Tennouga and B. Grassl, Res. Chem. Intermed., 2015, 41, 5839-5859.

13. A. Rabii, M. E. Zeynali and H. Baharvand, Iranian. Polym. J., 2005, 14, 603-608 .

14. A. Esau and P. Marek, Int. J. Miner. Process., 2009, 91, 50-54.

15. B. Bouras, T. Hocine, K. I. Benabadji, K. Benhabib and A. Mansri, Turk. J. Chem., 2018, 42, 748-758.

16. Y. H. Shen, J. Chem. Technol. Biotechnol., 2005, 80, 581-586.

17. Y. Zhen, Y. Hu, J. Ziwen, C. Tao, L. Haijianj, L. Aimin and C. Rongshi, J. Hazard. Mater., 2013, 254, 36-45.

18. A. Mansri, L. Tennouga and J. Desbrières, Euro. Polym. J., 2007, 43, 540-549.

19. R. Rahbari and J. François, Polymer, 1992, 33, 14491458.

20. A. Mansri, B. Bouras, L. Tennouga, G. Clisson and B. Grassl, Res. Chem. Intermed., 2014, 40, 269-279.

21. S. Changchaivong and S. Khaodhiar, Appl. Clay. Sci., 2009, 43, 317-321.

22. A. Mansri and N. Ramdani, Res. Chem. Intermed., 2015, 41, 1765-1776.

23. Q. Chang, X. Hao and L. Duan, J. Hazard. Mater., 2008, $15,548-553$.

24. A. Mansri, T. Hocine, B. Bouras and K. Benhabib, J. Macro. Sci. Part A. Pure and Appl.Chem., 2019, 56,96-103. 
